\title{
Consensus
}

\section{Group 4: Replacement therapy for adrenal insufficiency ${ }^{\text {th }}$}

\author{
Groupe 4 : traitement substitutif de l'insuffisance surrénale \\ Frédéric Castinetti $^{\mathrm{a}, *}$, Laurence Guignat ${ }^{\mathrm{b}}$, Claire Bouvattier $^{\mathrm{c}}$, Dinane Samara-Boustani ${ }^{\mathrm{d}}$, \\ Yves Reznik ${ }^{\mathrm{e}, \mathrm{f}}$ \\ ${ }^{a}$ UMR7286, CNRS, CRN2M, service d'endocrinologie, hôpital La Conception, Aix Marseille université, AP-HM, 13005 Marseille, France \\ ${ }^{\mathrm{b}}$ Service d'endocrinologie et maladies métaboliques, hôpital Cochin, CHU Paris Centre, 75014 Paris, France \\ ' Service d'endocrinologie de l'enfant, GHU Paris Sud, hôpital de Bicêtre, 94270 Le Kremlin-Bicêtre, France \\ ${ }^{\mathrm{d}}$ Service d'endocrinologie, gynécologie et diabétologie pédiatrique, hôpital Necker, CHU de Paris, 75015 Paris, France \\ e Service d'endocrinologie diabète et maladies métaboliques, CHU de Caen, 14032 Caen, France \\ ${ }^{\mathrm{f}}$ Université de Caen Normandie, 14032 Caen cedex, France
}

Keywords: Consensus; Addison's disease; Corticotropin deficiency; Adult; Children; Hydrocortisone; Fludrocortisone; DHEA

Mots clés : Consensus ; Maladie d'Addison ; Insuffisance corticotrope ; Adulte ; Enfant ; Hydrocortisone ; Fludrocortisone ; DHEA

\section{Glucocorticoid replacement}

\subsection{Background}

There are very few high quality studies on glucocorticoid replacement therapy in chronic adrenal insufficiency. This explains why multiple doses and dosage regimens, including time between doses and time of day of administration, have been reported (for example 13 different regimens used in a study of 50 patients with primary or secondary adrenal insufficiency, reported by Simon et al.) [1].

\subsection{Glucocorticoid molecules}

\subsubsection{Adult patients}

An international cohort study on 1245 patients with either primary $(84 \%)$ or secondary (16\%) adrenal insufficiency under-

DOIs of original articles: http://dx.doi.org/10.1016/j.ando.2017.10.005, http://dx.doi.org/10.1016/j.ando.2017.10.008, http://dx.doi.org/10.1016/j.ando. 2017.10.009, http://dx.doi.org/10.1016/j.ando.2017.10.010, http://dx.doi.org/ 10.1016/j.ando.2017.10.006

is SFE/SFEDP adrenal insufficiency consensus.

* Corresponding author.

E-mail address: frederic.castinetti@ap-hm.fr (F. Castinetti). lined that in most cases, current practice favors the use of hydrocortisone, which was chosen in $75 \%$ of cases (prednisone/prednisolone $11 \%$, cortisone acetate $6 \%$, dexamethasone $4 \%)$. These figures were similar in both primary and secondary adrenal insufficiency [2]. Hydrocortisone is a drug with a short half-life of 95 minutes, bioavailability of $95 \%$, a peak in plasma concentration reached at around 30-60 minutes after administration and its lowest plasma level 5 to 7 hours after administration. Hydrocortisone is eliminated in the form of free cortisol in the urine. North American and European consensus documents suggest the use of hydrocortisone or alternatively cortisone acetate. There is no data presently to show if cortisone acetate, which undergoes conversion to cortisol through the action of 11 betaHSD-1 in the liver, is superior or inferior to hydrocortisone [3,4]. It should be noted that this enzyme is inhibited by the GH/IGF1 system, and could be theoretically less efficient in patients with a deficit in GH replacement, although this was not reported in a retrospective cohort study published by Ragnarsson et al. [5]. Cortisone acetate is more readily accessible in some European countries, for example Italy [6]. Synthetic glucocorticoids, prednisolone and dexamethasone, are sometimes used in twice daily doses (5 $\mathrm{mg}$ prednisolone equivalent to $20 \mathrm{mg}$ hydrocortisone) or as a single dose $(0.5 \mathrm{mg}$ dexamethasone equivalent to $20 \mathrm{mg}$ hydrocortisone). Both of these molecules have a long half-life and prolonged glucocorticoid activity, and do not follow the 
normal circadian cycle of cortisol levels, leading to possible over-dosage side effects in the long-term. These drugs can be used in rare cases, such as:

- while blocking adrenal enzymes to obtain a more efficient inhibition of the corticotroph axis and adrenal androgens;

- in patients showing lower hydrocortisone activity due to more rapid pharmacokinetics.

\subsubsection{Pediatric patients}

The majority of available data on treatment of adrenal insufficiency relate to congenital adrenal hyperplasia. To date, there have been no controlled randomised trials of treatments for primary adrenal insufficiency, nor trials comparing different formulations of glucocorticoids. Glucocorticoid treatment has potential effects on both growth and puberty. In pediatric patients, the bioavailability of hydrocortisone was evaluated in 16 children with congenital adrenal hyperplasia and was reported to be approximately $94 \%$, with a peak plasma level reached 1-2 hours after administration and the lowest plasma level reached 7-9 hours after administration [7].

R4-1: In adults and children, we recommend the use of hydrocortisone as first line treatment of primary or secondary adrenal insufficiency. The treatment is a lifetime treatment except in special cases such as recovery from surgery for hypercorticism, or after stopping of glucocorticoid treatment.

Strong recommendation, level of evidence ++++ .

R4-2: In adult patients, first generation longacting glucocorticoids (prednisolone, dexamethasone) should not be used except in the case of poor efficacy of hydrocortisone due to its pharmacokinetics. In children, they should not be used except on specialist advice.

Weak recommendation, level of evidence ++.

\subsection{Dosage}

\subsubsection{Adult patients}

The replacement dose recommended at the start of treatment, initially suggested to be $9-11 \mathrm{mg} / \mathrm{m}^{2} / \mathrm{day}$ [8], is now considered too high, with current estimations in the order of $5.7-7.4 \mathrm{mg} / \mathrm{m}^{2} /$ day, leading to a theoretical dose of $10-25 \mathrm{mg} /$ day [9-11]. The optimal dose should be as low as possible, but the way in which this dose is determined in each case remains open for discussion. Mah et al. proposed using a dose correlated to patient weight based on an open, non-comparative study of 20 patients, later confirmed with 40 additional patients [12]. They used a hydrocortisone tablet, divided into 4 to arrive at the correct dosage, but the difficulty in breaking a $10 \mathrm{mg}$ hydrocortisone tablet into 4 means that this approach is problematic.

What are the problems associated with high doses of hydrocortisone? Patients with adrenal insufficiency have an increased mortality as a result of increased cardiovascular pathologies and infections [13-15]. Zueger et al. showed in a retrospective study of 105 patients with corticotroph deficiency that mortality was positively correlated with the daily dose of hydrocortisone and the dose by weight [16]. A supraphysiological dose of hydrocortisone has both metabolic and cardiovascular effects. Filipsson et al. showed, in a large retrospective cohort study of 2424 patients with secondary adrenal insufficiency, that a dose of $>20 \mathrm{mg}$ /day of hydrocortisone was associated with an unfavorable lipid profile, with an increase in LDL cholesterol and triglycerides [17].

In terms of skeletal health, an older study on a small number of patients $(n=12)$ reported that a reduction in the dose of hydrocortisone from 30 to $20 \mathrm{mg} / \mathrm{day}$ did not result in a significant difference in bone density even if a small number of subjects $(n=4)$ showed an increase in lumbar vertebral bone density [18]. In the same study, a weak correlation was reported between the reduction in hydrocortisone dose and a significant increase in osteocalcin level. Conversely, a recent German study on 57 patients showed a variation of $8-10 \mathrm{mg}$ in the daily dose of hydrocortisone over 2 years had a significant impact on bone mineral density [19]. Behan et al. showed, in an open crossover study looking at markers of bone turnover and three different doses of hydrocortisone (20-10/10-10/10-5 mg/day), that the weakest dose was associated with an increase in bone formation [20].

In terms of quality of life, Ragnarsson et al. showed in a retrospective cohort study of 2737 patients, that the quality of life index was lowest in patients with corticotroph deficiency treated with $>25 \mathrm{mg} /$ day hydrocortisone and highest in patients treated with $10 \mathrm{mg} / \mathrm{day}$ [5]. This confirms the quality of life data reported in 2 prospective crossover studies on a total of 200 patients [21,22]. In contrast, Werumeus Buning et al. found no alterations in cognitive function in patients treated with $15-20$ vs. $30-40 \mathrm{mg}$ daily hydrocortisone in a prospective randomised crossover study [23]. Finally, Benson et al. evaluated the impact on quality of life of 3 different regimens (hydrocortisone $10 / 0 / 5 / 0$ vs. hydrocortisone $10 / 5 / 0 / 5$ vs. prednisone $5 \mathrm{mg}$ in the morning) in a randomised, double-blind crossover study on 12 patients. After 4 weeks of treatment, there was an improvement in quality of life measures in patients using the first treatment regimen, and more pronounced in the afternoon [24]. In contrast, Alonso et al. found no significant difference in quality of life measures when they compared two regimens (20-0-20 mg/day vs. $10-5-5 \mathrm{mg} /$ day) in a three-month prospective crossover study of 12 patients, though the hydrocortisone dosage was elevated in both treated groups [25].

In terms of drug interactions, the use of hydrocortisone concomitantly with inducers of CYP3A4 requires an increased dose of glucocorticoids. These interactions are mainly with rifampicin, ketoconazole, some barbiturates or 
anti-epileptics (phenytoin, carbamazepine). Conversely, some molecules inhibit CYP3A4, for example ritonavir, fluoxetine, diltiazem and cimetidine. Grapefruit juice and licorice have also been reported to increase the level of bioavailable cortisol.

Mitotane is a powerful inducer of CYP3A4, and it also increases CBG. The dose of hydrocortisone thus needs to be doubled or tripled in the case of long-term use of mitotane. Estrogens also increase CGB [26], but do not necessitate an increase in dose of hydrocortisone. Finally, GH treatment can necessitate an increase in hydrocortisone dose, although exenatide can cause reduced intestinal absorption of hydrocortisone [27].

\subsubsection{Pediatric patients}

The physiological secretion of cortisol in basal conditions has been determined in children and adolescents without significant modification of puberty to be $5-6 \mathrm{mg} / \mathrm{m}^{2} /$ day, leading to a higher theoretical hydrocortisone dose of $9-12 \mathrm{mg} /$ day [28] in primary adrenal insufficiency and less in corticotroph insufficiency (bioavailability being reduced by intra-gastric degradation and passage through the liver) [29]. A higher dose of hydrocortisone is often necessary to reduce hyperandorgenic state in congenital adrenal hyperplasia. A supraphysiological dose of hydrocortisone can have an effect on stature; Bonfig et al. reported, in 125 children with primary adrenal insufficiency due to congenital adrenal hyperplasia, that a dose of $>20 \mathrm{mg} / \mathrm{m}^{2} /$ day was associated with a reduction in pubertal maximum height [30].

R4-3: In the adult patient, we recommend the lowest possible replacement dose of hydrocortisone that is tolerated to treat adrenal insufficiency, keeping in mind that a dose of $15-25 \mathrm{mg} /$ day is used as replacement in primary adrenal insufficiency (Addison's disease). [We recommend a lower dose (10-20 mg/day) to substitute for corticotroph deficiency]. In children, for primary adrenal insufficiency due to $\mathrm{CAH}$, we recommend a dose of hydrocortisone of $10-18 \mathrm{mg} / \mathrm{m}^{2} /$ day, higher in the neonatal period $\left(20-40 \mathrm{mg} / \mathrm{m}^{2} /\right.$ day during the first month) and in other cases of primary adrenal insufficiency a dose of $8-15 \mathrm{mg} / \mathrm{m}^{2} /$ day. We recommend a lower dose $\left(8-10 \mathrm{mg} / \mathrm{m}^{2} /\right.$ day) in the case of corticotroph deficiency with the highest dose in babies prior to weaning.

Strong recommendation, level of evidence +++.

\subsection{Timing of administration}

\subsubsection{Adult patients}

There is no current oral treatment that reproduces the circadian rhythm of cortisol; that is a peak in the morning on waking and a lowest concentration at midnight. This circadian rhythm is of theoretical importance since cortisol induces the activation of a number of clock genes in target tissues (in a second messenger role) [31]. Hydrocortisone must be delivered in 2 or 3 doses per day, the first and highest dose on waking and the last (in the case of a 3 dose regimen) 4 to 6 hours before going to bed. An international cohort study of 1245 patients with primary adrenal insufficiency $(84 \%)$ or secondary adrenal insufficiency $(16 \%)$ underlined that the majority of patients were on a 2 or 3 dose regimen ( $42 \%$ and $32 \%$ ) while other regimens were less common (one dose, 10\%, other regimens, 17\%) [2]. Neither of the two most common therapeutic regimens were shown to be better, but the number of comparative studies is quite small $[21,32,33]$. Bleicken et al. reported no difference in quality of life measures in a study of 334 patients with primary or secondary adrenal insufficiency taking either two or three dose regimens of hydrocortisone [21]. This study, however, was based on responses to a number of voluntary questionnaires. Kluger et al. did not identify the dosing regimen for hydrocortisone as a factor that influenced quality of life, in a study of Finnish patients with adrenal insufficiency, though a comparison of dosing schedule was a secondary aim for the study [33].

1.4.1.1. Continuous subcutaneous infusion. In 2007, a pilot study was published, describing the use of subcutaneous delivery of hydrocortisone using a portable pump (similar to that used in type I diabetes treatment), which was able to restore glucocorticoid circadian rhythm [34]. In spite of this, the recent data on efficacy in terms of quality of life for patients receiving this treatment are contradictory. Gagliardi et al. published a randomised crossover study on 10 patients comparing oral treatment with hydrocortisone and continuous subcutaneous infusion via a pump. The pharmacokinetic data showed a peak of cortisol in the morning when using the subcutaneous delivery that was not obtained with oral administration. Despite this, there was no change in subjective quality of life measures for these patients and at the end of the short-term study (4 weeks) only $50 \%$ of the patients wished to continue with subcutaneous treatment. It should also be noted that 17 of the selected patients refused the hydrocortisone implant treatment [35]. Conversely, a randomised open crossover study on 33 patients over 3 months, comparing the same treatment modalities found a clear improvement in quality of life measures (AddiQoL scale) favoring the subcutaneous treatment; though the level of proof was weaker given the open nature of the study [36]. No data on comorbidities during prolonged subcutaneous delivery of treatment are currently available, which makes it difficult to judge the overall benefit of restoring the circadian rhythm in patients.

1.4.1.2. New molecules. A modified-release hydrocortisone (Plenadren ${ }^{(1)}$ ) has recently been authorised for use in Europe for patients with adrenal insufficiency. This formulation gives a release profile that is more physiological across the day, with two components, one that is rapidly released and the other resulting in prolonged release over 12 hours. It does not, however, mimic the peak of cortisol secretion on 
waking. A pilot randomized prospective crossover study showed that the long release formulation resulted in a physiological peak of cortisol 50 mins after administration and a concentration of $>200 \mathrm{nmol} / \mathrm{L}$ over 6 hours, thus mimicking physiological plasma cortisol levels [37]. In an open prospective study in a single center, on 50 patients treated with hydrocortisone, 30 patients showed a benefit with replacement by Plenadren ${ }^{\circledR}$ after a mean duration of 6 months, with a significant reduction in BMI and HbA1c, compared to patients treated with classical hydrocortisone. The Plenadren ${ }^{\circledR}$ treated patients also showed no change in quality of life measures while the patients on classical hydrocortisone treatment showed a reduction in quality of life [38]. These results confirm those of a prospective randomized pilot study published in 2012, on 64 patients who benefitted from a crossover from hydrocortisone to Plenadren ${ }^{\circledR}$. This study validated, for the first time, the release profile of the molecule, and in secondary criteria, a significant difference in terms of weight loss, blood pressure and HbA1c after 12 weeks of Plenadren ${ }^{\circledR}$ treatment compared to classic hydrocortisone administration [39].

Another modified-release hydrocortisone (Chronocort $\left.{ }^{(}\right)$is currently being evaluated for the indication 'adrenal enzymatic block'. One administration in the evening at $10 \mathrm{pm}$ resulted in a physiological increase in cortisol during the night. A pharmacokinetic proof of concept study was published in 2007, based on 6 healthy volunteers in whom the endogenous cortisol secretion was blocked by administration of dexamethasone. This study showed the potential for producing, with this drug, a physiological increase in nocturnal concentration and a peak of cortisol in the morning on waking [40].

\subsubsection{Pediatric patients}

The dose of hydrocortisone is divided into 2 or 3 administrations per day, the first and highest dose on waking and the last dose taken before bed. In congenital adrenal hyperplasia, neither of these therapeutic protocols compensates for the hyperandrogenic state late at night [41].

In 2011, restoration of the circadian rhythm through subcutaneous delivery of hydrocortisone via a pump was reported in an adolescent patient with congenital adrenal hyperplasia [42]. The use of subcutaneous hydrocortisone delivered by pump was then reported in a study of three adolescents with congenital adrenal hyperplasia and rapid clearance of cortisol. Continuous administration of cortisol, following a normal physiological circadian rhythm, normalized concentrations of $17 \mathrm{OH}$ progesterone and androstenedione. Bolus delivery of hydrocortisone allowed episodes of stress or fever to be covered. Technical problems with the pump were rare and manifested as headaches and nausea in the patients. The duration of treatment with the pump was not reported but an improvement in absenteeism, quality of life and sporting activity was noted by the authors [43]. No data is available on long-term benefit of treatment in adolescent patients.
R4-4: In adults and children, we suggest that the dose of hydrocortisone is divided into 2 or 3 administrations per day, with the highest dose in the morning. A regimen of 3 doses is recommended in babies and young children.

Weak recommendation, level of evidence ++ .

R4-5: In adults, we do not recommend the use of prolonged release hydrocortisone or hydrocortisone delivered by subcutaneous pump. In children, we do not recommend glucocorticoids other than hydrocortisone, nor hydrocortisone in suspension.

Weak recommendation: expert opinion.

\subsection{Treatment surveillance}

\subsubsection{Adult patients}

Clinical surveillance of treatment consists of examination for signs of overdose (weight gain, skin fragility, hypertension) or under-dosage (fatigue, nausea, myalgia, hypotension), alteration in daily activities and modifications to sleep quality. The evaluation of quality of life measures with the AddiQoL scale, allows the impact of replacement treatment to be evaluated in patients with Addison's disease [44]. Other studies have examined diverse biological markers with a view to individualizing replacement therapy. These include:

- plasma cortisol: there is a large variation in concentration for a given individual and between individuals, making it difficult to use the same reference values for all patients. Furthermore, there are also gender- and age-related differences. Arlt et al. compared curves of plasma cortisol (3 samples taken across the day) in 46 patients with primary or secondary adrenal insufficiency, to determine if the level of cortisone acetate should be considered optimal or not and reported that despite plasma levels being considered optimal in 37 patients, 5 patients presented clinical signs of over-dosage and 4 of under-dosage. The authors therefore did not show a benefit of plasma measurements over observation of clinical signs [45]. Peacey et al. measured plasma cortisol, in a prospective observational study on 32 patients with primary or secondary adrenal insufficiency under treatment, which had the following objectives: (1) a peak in cortisol between 9 am and 12 $\mathrm{pm}<650 \mathrm{nmol} / \mathrm{L}$ and between $6 \mathrm{pm}$ and $9 \mathrm{pm}<250 \mathrm{nmol} / \mathrm{L}$; (2) a mean plasma cortisol measured at 6 time-points across the day of between 150 and $300 \mathrm{nmol} / \mathrm{L}$; (3) a level of $24 \mathrm{hr}$ free urinary cortisol in the normal range [18]. However, new assay kits have made these threshold levels difficult to determine, the levels given above are indicative and need to be balanced with the threshold levels of each kit that is used $[46,47]$. Some authors have proposed measuring peak plasma 
cortisol, the cycle of plasma levels over $24 \mathrm{hrs}$ or to use the area under the curve [48]. Mah et al. recommend using the plasma cortisol level $4 \mathrm{hrs}$ after the morning administration, allowing an estimation of over-dosage or under-dosage using standard values based on control subjects and with dose correlated to body weight [12]. Simon et al. proposed the proof of concept pharmacokinetic model, using 500 patients, to individualise hydrocortisone treatment and based on target plasma cortisol levels at 8 am, $4 \mathrm{pm}$ and midnight [1]. Data on improvements in metabolic parameters and quality of life in these patients were not included in the published study. A study by Rousseau et al. showed a good correlation between plasma cortisol measured at 10 am and the area under curve measured for cortisol between 8 am and $7 \mathrm{pm}$ in 27 patients with Addison's disease treated with hydrocortisone taken in 3 doses per day. These authors showed that cortisol level at $10 \mathrm{am}$ was a good predictor of the diurnal physiological profile of plasma cortisol, using healthy volunteers as a reference [49];

- 24 hour urinary free cortisol: UFC is affected by the saturation of CBG (a strong increase in UFC is seen in this case, even if plasma cortisol is low) and is thus not useful for adjusting the dose of hydrocortisone;

- salivary cortisol is a cheap, feasible and reproducible test. Ceccato et al. evaluated its use in adaptation of cortisone acetate treatment in 28 patients with corticotroph deficiency compared to 36 healthy controls. The assay of salivary cortisol 90 minutes after each dose was used to determine area under curve, which in comparison with control subject values could show over-dosage or under-dosage. It should be noted that patients with an area under curve higher than the control 97.5th percentile showed no obvious signs of overdose [50]. Conversely, Thomson et al. showed great variability in salivary cortisol in a crossover study of 27 patients being treated with hydrocortisone (oral or IV), and did not show a good correlation between plasma and saliva levels, making it difficult to employ in current practice [51];

- cortisol in hair: hair growth $(1 \mathrm{~cm}$ per month) and the correlation between cortisol level in the hair and exposure to glucocorticoids could allow detection of overdose or underdosage in patients with adrenal insufficiency. A pilot study showed no significant difference between patients and female control subjects, but a difference was observed between male subjects [52];

- plasma ACTH: plasma ACTH does not assist in evaluating glucocorticoid replacement therapy with classic rapid release hydrocortisone since ACTH is always high in the morning on waking and then decreases rapidly after administration of hydrocortisone in primary adrenal insufficiency [53]. In the study by Rousseau et al., the amplitude of the fall in ACTH after the morning administration of hydrocortisone correlated less well with area under the curve for cortisol than cortisol measured at the morning peak of 10 am [49].

\subsubsection{Pediatric patients}

Clinical surveillance of treatment is used (growth, puberty) and observation of signs of overdose (weight gain, hypertension) or signs of under-dosage (fatigue, change in daily activity). In congenital adrenal hyperplasia, assay for $17 \mathrm{OH}$ progesterone, androstenedione and testosterone in the morning can assist in evaluating therapy [54]. The assay of $17 \mathrm{OH}$ progesterone and androstenedione in hair is currently being evaluated in congenital adrenal hyperplasia [55].

R4-6: In adults, we recommend surveillance of treatment based on clinical signs of overdose or under-dosage. We do not recommend routine use of biochemical markers for adjustment of replacement therapy. In children, we recommend clinical surveillance (growth, puberty) and observation of clinical signs of overdose and under-dosage. We do not recommend routine use of biochemical markers for adjustment of replacement therapy, except in the case of congenital adrenal hyperplasia, where we recommend regular assay of biochemical markers [see National Guidelines for Diagnosis and Treatment of congenital adrenal hyperplasia, (PNDS) 2011].

Strong recommendation, level of evidence +++.

\subsection{Management during pregnancy}

Plasma cortisol levels rise during pregnancy due to an increase in CBG. Free cortisol also rises during the 3rd trimester due to placental secretion of $\mathrm{CRH}$ and an increase in the response to ACTH [56]. There are currently no data that suggest a necessity to increase or decrease the dose of hydrocortisone during pregnancy, particularly in the 3 rd trimester. Around delivery, it has been suggested that the dose of hydrocortisone should be doubled or should be administered by injection of $100-200 \mathrm{mg}$ each $24 \mathrm{hrs}$. A normal dosage regimen can then be reinstated 48 $\mathrm{hr}$ after delivery. Lactation is not a contra-indication even though there is a possibility of a small level of transfer of hydrocortisone from maternal milk [57].

R4-7: We suggest that around time of delivery, the dose of hydrocortisone should be increased and administered by IV drip in cases of digestive intolerance.

Weak recommendation, level of evidence ++ . 


\section{Mineralocorticoid replacement}

Mineralocorticoid replacement must be considered in Addison's disease, though it is not useful in the case of corticotroph insufficiency, since ACTH is only a minor regulator of aldosterone secretion. There are currently no studies with a strong level of evidence on the subject of mineralocorticoid replacement.

\subsection{In adults}

\subsubsection{Justification}

The majority of patients with Addison's disease require steroid replacement treatment with some mineralocorticoid component due to the risk of loss of sodium in urine, volume depletion from the vasculature and hyperkalemia. Rare patients are well controlled by hydrocortisone alone, which has a mineralocorticoid action $(20 \mathrm{mg}$ hydrocortisone $=50 \mu \mathrm{g}$ fluorohydrocortisone) [58]. The cause is not unequivocal; incomplete mineralocorticoid deficiency, supraphysiological dose of hydrocortisone, weak activity of $11 \beta$ hydroxy steroid dehydrogenase 2 which converts cortisol to cortisone. In contrast, other glucocorticoids have only a weak mineralocorticoid action, for example prednisolone; or no MC action, for example dexamethasone. The use of these latter two compounds thus requires addition of mineralocorticoid replacement [59].

\subsubsection{Mineralocorticoid adjustment}

Fludrocortisone (9-alpha-fluorohydrocortisone, flucortac ${ }^{\circledR}$ ) is a synthetic compound with a strong mineralocorticoid activity, administered by oral route with a single daily dose. The mean daily dose is $100 \mu \mathrm{g} /$ day (50-200 in adults). Mineralocorticoid replacement may need to be increased in hot or humid climates that lead to excessive sweating. Concomitantly, daily salt intake must be ample in Addison's patients and increased in the case of intense physical activity. Adaptation of mineralocorticoid replacement needs to be personalised and the patient needs to be educated on how to adjust replacement therapy as required.

\subsubsection{Parameters for surveillance}

Replacement with mineralocorticoids requires clinicobiochemical surveillance of patients. Decreased blood pressure, orthostatic hypotension, excessive sodium consumption (salt craving) or episodes of nausea can be signs of under-dosage. Blood ion profiles can show hyponatremia and/or hyperkalemia. Conversely, hypertension, edema and hypokalemia justify a reduction rather than an interruption in mineralocorticoid replacement, in conjunction with a reevaluation of dietary ion intakes [60-62].

Measurement of plasma renin constitutes the most precise marker of sodium balance and effective plasma volume [63], where there is an inverse relationship between plasma renin activity and plasma volume $[59,64]$. Measurement of renin activity or direct assay of plasma renin can be performed at any time, independent of the time of fludrocortisone administration [64]. The assay for renin needs to be performed from the initiation of mineralocorticoid replacement, during the period of dose titration until the dose is satisfactorily adjusted and then annually. In the case of mineralocorticoid overdose, sodium and fluid retention has a negative feedback on renin secretion. Strict normalization of renin should be avoided since this leads to a risk of edema and hypokalemia [64]. Plasma renin should therefore be maintained at a high level or slightly above normal levels $[58,59]$.

\subsubsection{Essential hypertension, cardiac insufficiency, pregnancy}

In patients with Addison's disease who are also hypertensive independent of a level of mineralocorticoid replacement that is too high, the dose of fludrocortisone should be reduced before the introduction of an anti-hypertensive. The first line drug of choice in this case is an angiotensin converting enzyme (ACE) inhibitor or an angiotensin-2 receptor antagonist and the second line drug a calcium antagonist. Diuretics, particularly antagonists of the mineralocorticoid receptor, are contraindicated [61]. In the case of associated cardiac insufficiency, a reduction or cessation of fludrocortisone and addition of a loop diuretic is suggested.

During pregnancy, plasma renin assay cannot be used due to the physiological elevation of renin of placental origin. In the last trimester, the dose of fludrocortisone may be increased in view of the anti-mineralocorticoid activity of circulating progesterone $[65,66]$.

\subsubsection{Drug interactions}

The use of drugs including diuretics, acetazolamide, carbenoxolone, non-steroidal anti-inflammatories and drospirenone, with fludrocortisone makes it necessary to adjust the mineralocorticoid replacement. Inhibitors of cytochrome $\mathrm{P} 450$ accelerate the catabolism of fludrocortisone; conversely inhibitors of cytochrome $\mathrm{P} 450$ such as phenytoin and phenobarbital reduce catabolism. Licorice and grapefruit juice both potentiate the mineralocorticoid action of hydrocortisone and thus should be avoided [67].

\subsection{Pediatric patients}

Fludrocortisone is administered orally and in one dose (adolescent) or two doses at a dose of $50-100 \mathrm{mg} /$ day. Oral supplementation with sodium is needed in babies up to 1-2 years of age (1-2 $\mathrm{g} \mathrm{NaCl} /$ day in 3-4 administrations) due to the immaturity of the kidneys at this age (resistance to mineralocorticoids) and the low levels of salt in maternal milk and in baby formula. Clinicobiochemical surveillance of mineralocorticoid replacement in pediatric patients is required, similar to that in adult patients with particular attention paid to growth curve in young children. Regular measurement of blood pressure is necessary as hypertension is reported in $12-50 \%$ of children with congenital adrenal hyperplasia treated with fludrocortisone [68]. 
R4-8: In adults, we recommend mineralocorticoid replacement using fludrocortisone and a mean dose of $100 \mu \mathrm{g} /$ day (individually adjusted) and a free intake of dietary sodium in patients with primary adrenal insufficiency with mineralocorticoid deficiency. Patients with corticotroph insufficiency should not be treated with replacement drugs with a mineralocorticoid component.

Strong recommendation, level of evidence +++. In children, we recommend mineralocorticoid replacement using fludrocortisone at a dose of 50-100 $\mu \mathrm{g} /$ day. One oral administration of sodium (1-2 $\mathrm{g} /$ day) is necessary up to $1-2$ yrs of age in children with primary adrenal insufficiency with mineralocorticoid deficiency. Children with corticotroph insufficiency should not be treated with mineralocorticoid replacement.

Strong recommendation, level of evidence ++ .

R4-9: In adults, we recommend that surveillance and adjustment of mineralocorticoid replacement be based on clinical and biochemical signs of under-dosage (increased salt appetite, hypotension, nausea, hyponatremia, hyperkalemia, elevated renin) or of overdose (hypertension, edema, hypokalemia, undetectable or lower than normal renin).

Strong recommendation, level of evidence +++. In children, we recommend surveillance and adjustment of mineralocorticoid replacement based, as in adult patients, on clinical and biochemical signs of under-dosage and equally on particular surveillance of growth curves in young children. We recommend maintenance of plasma renin at values from normal to higher than normal levels.

Strong recommendation, level of evidence ++ .

\section{Androgen replacement}

\subsection{Adult patients}

\subsubsection{Androgen deficiency in adrenal insufficiency}

In women, the adrenal cortex is the major source of androgens including dehydroepiandrostenedione (DHEA), its sulfated form S-DHEA as well as androstenedione. The adrenal androgens are thus responsible for androgenic physiological effects, including their androgenic actions after conversion into their active compounds and also their neurosteroid properties, notably their regulatory effects on mood.
Numerous patients with Addison's disease report deterioration in their general state of health despite glucocorticoid and mineralocorticoid replacement. Patients with either primary or secondary adrenal insufficiency are reported to perceive a change in their state of health $[22,69]$.

\subsubsection{Replacement with DHEA}

Female patients with Addison's disease have a lower level of plasma DHEA which can be corrected by DHEA replacement. In parallel, their scores for depression and anxiety, sense of well-being and perception of sexual function and libido are improved by replacement therapy [70]. Prolonged use of DHEA in both males and females has favorable effects on quality of life, femoral bone density and lean body mass [71]. DHEA modifies the lipid profile, reducing LDL cholesterol, triglycerides and also HDL cholesterol as well as the particle size of HDL, though the impact of these changes on cardiovascular risk is unknown [72]. Adrenal insufficiency of central origin affects the level of circulating androgens and DHEA replacement in women with pituitary insufficiency improves libido and sexual function [73]. Meta-analysis of the effects of DHEA in women found a modest benefit in quality of life and depression [74]. The principle unwanted effects of DHEA replacement are androgenic including hirsutism, seborrheic skin, acne and an androgenic sweat odor [74]. The effect of DHEA on deterioration of quality of life in patients with hypopituitarism is small but the impact of a deficit in only ACTH on the quality of life of these patients is not known [75]. There are no solid data concerning the beneficial effects of androgen replacement in male subjects with adrenal insufficiency.

\subsubsection{Prescription, surveillance}

The formulations of DHEA that are found on the market contain variable quantities of DHEA and are not always well controlled. The quality of commercial formulations should therefore be assured or alternatively, formulations should be prepared by a compounding pharmacy.

In practice, androgenic treatment by DHEA can be proposed for female patients presenting with symptoms of androgen deficit or low plasma DHEA level. One to 3 months after commencing treatment with DHEA replacement $(25 \mathrm{mg}$ in the morning), efficacy should be evaluated by assay of plasma DHEA $24 \mathrm{hrs}$ after the last administration. Efficacy is evaluated by improvement in symptoms of androgen deficit and a plasma level of DHEA that is in the median range for normal subjects. In the absence of clinical efficacy after adjusting the dose of DHEA $(50 \mathrm{mg} / \mathrm{day})$, the replacement treatment should be stopped after 3 to 6 months. In case of adverse effects, the dose can be reduced by half or the treatment stopped.

\subsection{Pediatric patients}

The use of androgen supplementation has not been evaluated. 
R4-10: We suggest that androgen replacement be envisaged in women with primary or secondary adrenal insufficiency who are suffering from an alteration in quality of life, problems with mood and a loss of libido despite optimal glucocorticoid and mineralocorticoid replacement.

Weak recommendation, level of evidence ++ .

R4-11: The initial dose of DHEA for androgen replacement should be $25-50 \mathrm{mg} /$ day over a period of 3 to 6 months, with adjustment of the dose as a function of (i) circulating levels of plasma DHEA during replacement treatment and (ii) the effects on symptoms identified prior to treatment. In the absence of a beneficial effect or in the case of adverse effects of androgen treatment, replacement therapy should be ceased.

Weak recommendation, level of evidence ++.

\section{Disclosure of interest}

F. Castinetti has performed conferences for HAC Pharma, Shire and Viropharma.

L. Guignat was a consultant for Viropharma and has performed conferences for HAC Pharma.

C. Bouvattier, D. Samara Boustani declare that they have no competing interest.

Y. Reznik was a consultant for Viropharma, and Shire and has performed conferences for HAC Pharma and Viropharma.

\section{References}

[1] Simon N, Castinetti F, Ouliac F, Lesavre N, Brue T, Oliver C. Pharmacokinetic evidence for suboptimal treatment of adrenal insufficiency with currently available hydrocortisone tablets. Clin Pharmacokinet 2010;49:455-63.

[2] Forss M, Batcheller G, Skrtic S, Johannsson G. Current practice of glucocorticoid replacement therapy and patient-perceived health outcomes in adrenal insufficiency - a worldwide patient survey. BMC Endocr Disord 2012;12:8.

[3] Bornstein SR, Allolio B, Arlt W, Barthel A, Don-Wauchope A, Hammer GD, et al. Diagnosis and treatment of primary adrenal insufficiency: an Endocrine Society Clinical Practice Guideline. J Clin Endocrinol Metab 2016;101:364-89.

[4] Husebye ES, Allolio B, Arlt W, Badenhoop K, Bensing S, Betterle C, et al. Consensus statement on the diagnosis, treatment and follow-up of patients with primary adrenal insufficiency. J Intern Med 2014;275:104-15.

[5] Ragnarsson O, Mattsson AF, Monson JP, Filipsson Nystrom H, Akerblad AC, Koltowska-Haggstrom M, et al. The relationship between glucocorticoid replacement and quality of life in 2737 hypopituitary patients. Eur J Endocrinol 2014;171:571-9.

[6] Betterle C, Scarpa R, Garelli S, Morlin L, Lazzarotto F, Presotto F, et al. Addison's disease: a survey on 633 patients in Padova. Eur J Endocrinol 2013;169:773-84.

[7] Charmandari E, Johnston A, Brook CG, Hindmarsh PC. Bioavailability of oral hydrocortisone in patients with congenital adrenal hyperplasia due to 21-hydroxylase deficiency. J Endocrinol 2001;169:65-70.
[8] Cope CL, Black E. The production rate of cortisol in man. Br Med J $1958 ; 1: 1020-4$

[9] Esteban NV, Loughlin T, Yergey AL, Zawadzki JK, Booth JD, Winterer JC, et al. Daily cortisol production rate in man determined by stable isotope dilution/mass spectrometry. J Clin Endocrinol Metab 1991;72:39-45.

[10] Metzger DL, Wright NM, Veldhuis JD, Rogol AD, Kerrigan JR. Characterization of pulsatile secretion and clearance of plasma cortisol in premature and term neonates using deconvolution analysis. J Clin Endocrinol Metab 1993; 77:458-63.

[11] Arlt W, Allolio B. Adrenal insufficiency. Lancet 2003;361:1881-93.

[12] Mah PM, Jenkins RC, Rostami-Hodjegan A, Newell-Price J, Doane A, Ibbotson $\mathrm{V}$, et al. Weight-related dosing, timing and monitoring hydrocortisone replacement therapy in patients with adrenal insufficiency. Clin Endocrinol 2004:61:367-75.

[13] Rosen T, Bengtsson BA. Premature mortality due to cardiovascular disease in hypopituitarism. Lancet 1990;336:285-8.

[14] Druce MR, Akker SA, Chew SL, Drake WM, Grossman AB. Morbidity in patients on long-term steroid replacement therapy. Clin Endocrinol 2010;72:564-6.

[15] Bergthorsdottir R, Leonsson-Zachrisson M, Oden A, Johannsson G. Premature mortality in patients with Addison's disease: a population-based study. J Clin Endocrinol Metab 2006;91:4849-53.

[16] Zueger T, Kirchner P, Herren C, Fischli S, Zwahlen M, Christ E, et al. Glucocorticoid replacement and mortality in patients with nonfunctioning pituitary adenoma. J Clin Endocrinol Metab 2012;97:E1938-42.

[17] Filipsson H, Monson JP, Koltowska-Haggstrom M, Mattsson A, Johannsson G. The impact of glucocorticoid replacement regimens on metabolic outcome and comorbidity in hypopituitary patients. J Clin Endocrinol Metab 2006;91:3954-61.

[18] Peacey SR, Yuan Guo C, Eastell R, Weetman AP. Optimization of glucocorticoid replacement therapy: the long-term effect on bone mineral density. Clin Endocrinol 1999;50:815-7.

[19] Schulz J, Frey KR, Cooper MS, Zopf K, Ventz M, Diederich S, et al. Reduction in daily hydrocortisone dose improves bone health in primary adrenal insufficiency. Eur J Endocrinol 2016;174:531-8.

[20] Behan LA, Kelleher G, Hannon MJ, Brady JJ, Rogers B, Tormey W, et al Low-dose hydrocortisone replacement therapy is associated with improved bone remodelling balance in hypopituitary male patients. Eur J Endocrinol 2014;170:141-50.

[21] Bleicken B, Hahner S, Loeffler M, Ventz M, Decker O, Allolio B, et al. Influence of hydrocortisone dosage scheme on health-related quality of life in patients with adrenal insufficiency. Clin Endocrinol 2010;72: 297-304.

[22] Hahner S, Loeffler M, Fassnacht M, Weismann D, Koschker AC, Quinkler $\mathrm{M}$, et al. Impaired subjective health status in 256 patients with adrenal insufficiency on standard therapy based on cross-sectional analysis. J Clin Endocrinol Metab 2007;92:3912-22.

[23] Werumeus Buning J, Brummelman P, Koerts J, Dullaart RP, van den Berg G, van der Klauw MM, et al. The effects of two different doses of hydrocortisone on cognition in patients with secondary adrenal insufficiency - results from a randomized controlled trial. Psychoneuroendocrinology 2015;55:36-47.

[24] Benson S, Neumann P, Unger N, Schedlowski M, Mann K, Elsenbruch S, et al. Effects of standard glucocorticoid replacement therapies on subjective well-being: a randomized, double-blind, crossover study in patients with secondary adrenal insufficiency. Eur J Endocrinol 2012;167:679-85.

[25] Alonso N, Granada ML, Lucas A, Salinas I, Reverter J, Oriol A, et al Evaluation of two replacement regimens in primary adrenal insufficiency patients. Effect on clinical symptoms, health-related quality of life and biochemical parameters. J Endocrinol Invest 2004;27:449-54.

[26] Qureshi AC, Bahri A, Breen LA, Barnes SC, Powrie JK, Thomas SM, et al. The influence of the route of oestrogen administration on serum levels of cortisol-binding globulin and total cortisol. Clin Endocrinol 2007;66:632-5.

[27] Fujita Y, Kitamura T, Otsuki M, Tamada D, Tabuchi Y, Kozawa J, et al. Exenatide alters absorption of hydrocortisone in a diabetic patient with panhypopituitarism: iatrogenic adrenal insufficiency. Diabetes Care 2013;36:e8. 
[28] Linder BL, Esteban NV, Yergey AL, Winterer JC, Loriaux DL, Cassorla F. Cortisol production rate in childhood and adolescence. J Pediatr 1990;117:892-6.

[29] Shulman DI, Palmert MR, Kemp SF, Lawson Wilkins D, Therapeutics C. Adrenal insufficiency: still a cause of morbidity and death in childhood. Pediatrics 2007;119:e484-94.

[30] Bonfig W, Pozza SB, Schmidt H, Pagel P, Knorr D, Schwarz HP. Hydrocortisone dosing during puberty in patients with classical congenital adrenal hyperplasia: an evidence-based recommendation. J Clin Endocrinol Metab 2009;94:3882-8

[31] So AY, Bernal TU, Pillsbury ML, Yamamoto KR, Feldman BJ. Glucocorticoid regulation of the circadian clock modulates glucose homeostasis. Proc Natl Acad Sci U S A 2009;106:17582-7.

[32] Ekman B, Bachrach-Lindstrom M, Lindstrom T, Wahlberg J, Blomgren J, Arnqvist HJ. A randomized, double-blind, crossover study comparing two- and four-dose hydrocortisone regimen with regard to quality of life, cortisol and ACTH profiles in patients with primary adrenal insufficiency. Clin Endocrinol 2012;77:18-25.

[33] Kluger N, Matikainen N, Sintonen H, Ranki A, Roine RP, Schalin-Jantti C. Impaired health-related quality of life in Addison's disease - impact of replacement therapy, comorbidities and socio-economic factors. Clin Endocrinol 2014;81:511-8.

[34] Lovas K, Husebye ES. Continuous subcutaneous hydrocortisone infusion in Addison's disease. Eur J Endocrinol 2007;157:109-12.

[35] Gagliardi L, Nenke MA, Thynne TR, von der Borch J, Rankin WA, Henley DE, et al. Continuous subcutaneous hydrocortisone infusion therapy in Addison's disease: a randomized, placebo-controlled clinical trial. J Clin Endocrinol Metab 2014;99:4149-57.

[36] Oksnes M, Bjornsdottir S, Isaksson M, Methlie P, Carlsen S, Nilsen RM, et al. Continuous subcutaneous hydrocortisone infusion versus oral hydrocortisone replacement for treatment of Addison's disease: a randomized clinical trial. J Clin Endocrinol Metab 2014;99:1665-74.

[37] Johannsson G, Bergthorsdottir R, Nilsson AG, Lennernas H, Hedner T, Skrtic S. Improving glucocorticoid replacement therapy using a novel modified-release hydrocortisone tablet: a pharmacokinetic study. Eur J Endocrinol 2009;161:119-30.

[38] Quinkler M, Miodini Nilsen R, Zopf K, Ventz M, Oksnes M. Modifiedrelease hydrocortisone decreases BMI and $\mathrm{HbA} 1 \mathrm{c}$ in patients with primary and secondary adrenal insufficiency. Eur J Endocrinol 2015;172:619-26.

[39] Johannsson G, Nilsson AG, Bergthorsdottir R, Burman P, Dahlqvist P, Ekman B, et al. Improved cortisol exposure-time profile and outcome in patients with adrenal insufficiency: a prospective randomized trial of a novel hydrocortisone dual-release formulation. J Clin Endocrinol Metab 2012;97:473-81

[40] Newell-Price J, Whiteman M, Rostami-Hodjegan A, Darzy K, Shalet S, Tucker GT, et al. Modified-release hydrocortisone for circadian therapy: a proof-of-principle study in dexamethasone-suppressed normal volunteers. Clin Endocrinol 2008;68:130-5.

[41] Frisch H, Parth K, Schober E, Swoboda W. Circadian patterns of plasma cortisol, 17-hydroxyprogesterone, and testosterone in congenital adrenal hyperplasia. Arch Dis Child 1981;56:208-13.

[42] Tuli G, Rabbone I, Einaudi S, di Gianni V, Tessaris D, Gioia E, et al. Continuous subcutaneous hydrocortisone infusion (CSHI) in a young adolescent with congenital adrenal hyperplasia $(\mathrm{CAH})$. J Pediatr Endocrinol Metab 2011;24:561-3.

[43] Hindmarsh PC. The child with difficult to control congenital adrenal hyperplasia: is there a place for continuous subcutaneous hydrocortisone therapy. Clin Endocrinol 2014;81:15-8.

[44] Giordano R, Guaraldi F, Marinazzo E, Fumarola F, Rampino A, Berardelli R, et al. Improvement of anthropometric and metabolic parameters, and quality of life following treatment with dual-release hydrocortisone in patients with Addison's disease. Endocrine 2016;51: 360-8.

[45] Arlt W, Rosenthal C, Hahner S, Allolio B. Quality of glucocorticoid replacement in adrenal insufficiency: clinical assessment vs. timed serum cortisol measurements. Clin Endocrinol 2006;64:384-9.

[46] Raverot V, Richet C, Morel Y, Raverot G, Borson-Chazot F. Establishment of revised diagnostic cut-offs for adrenal laboratory investigation using the new Roche Diagnostics Elecsys(R) Cortisol II assay. Ann Endocrinol (Paris) 2016;77:620-2.

[47] Kline GA, Buse J, Krause RD. Clinical implications for biochemical diagnostic thresholds of adrenal sufficiency using a highly specific cortisol immunoassay. Clin Biochem 2017;50:475-80.

[48] Debono M, Ross RJ, Newell-Price J. Inadequacies of glucocorticoid replacement and improvements by physiological circadian therapy. Eur J Endocrinol 2009;160:719-29.

[49] Rousseau E, Joubert M, Trzepla G, Parienti JJ, Freret T, Vanthygem MC, et al. Usefulness of time-point serum cortisol and ACTH measurements for the adjustment of glucocorticoid replacement in adrenal insufficiency. PloS One 2015;10:e0135975.

[50] Ceccato F, Albiger N, Reimondo G, Frigo AC, Ferasin S, Occhi $\mathrm{G}$, et al. Assessment of glucocorticoid therapy with salivary cortisol in secondary adrenal insufficiency. Eur J Endocrinol 2012;167: 769-76.

[51] Thomson AH, Devers MC, Wallace AM, Grant D, Campbell K, Freel $\mathrm{M}$, et al. Variability in hydrocortisone plasma and saliva pharmacokinetics following intravenous and oral administration to patients with adrenal insufficiency. Clin Endocrinol 2007;66:789-96.

[52] Gow R, Koren G, Rieder M, Van Uum S. Hair cortisol content in patients with adrenal insufficiency on hydrocortisone replacement therapy. Clin Endocrinol 2011;74:687-93.

[53] Romijn JA, Smit JW, Lamberts SW. Intrinsic imperfections of endocrine replacement therapy. Eur J Endocrinol 2003;149:91-7.

[54] Charmandari E, Matthews DR, Johnston A, Brook CG, Hindmarsh PC. Serum cortisol and 17-hydroxyprogesterone interrelation in classic 21hydroxylase deficiency: is current replacement therapy satisfactory? J Clin Endocrinol Metab 2001;86:4679-85.

[55] Noppe G, de Rijke YB, Koper JW, van Rossum EF, van den Akker EL. Scalp hair 17-hydroxyprogesterone and androstenedione as a long-term therapy monitoring tool in congenital adrenal hyperplasia. Clin Endocrinol (Oxf) 2016;85:522-7.

[56] Allolio B, Hoffmann J, Linton EA, Winkelmann W, Kusche M, Schulte HM. Diurnal salivary cortisol patterns during pregnancy and after delivery: relationship to plasma corticotrophin-releasing-hormone. Clin Endocrinol 1990;33:279-89.

[57] Lindsay JR, Nieman LK. The hypothalamic-pituitary-adrenal axis in pregnancy: challenges in disease detection and treatment. Endocr Rev 2005;26:775-99.

[58] Oelkers W, Diederich S, Bahr V. Diagnosis and therapy surveillance in Addison's disease: rapid adrenocorticotropin (ACTH) test and measurement of plasma ACTH, renin activity, and aldosterone. J Clin Endocrinol Metab 1992:75:259-64.

[59] Smith SJ, MacGregor GA, Markandu ND, Bayliss J, Banks RA, Prentice $\mathrm{MG}$, et al. Evidence that patients with Addison's disease are undertreated with fludrocortisone. Lancet 1984;1:11-4.

[60] Jadoul M, Ferrant A, De Plaen JF, Crabbe J. Mineralocorticoids in the management of primary adrenocortical insufficiency. J Endocrinol Invest 1991;14:87-91

[61] Knowlton AI, Baer L. Cardiac failure in Addison's disease. Am J Med 1983;74:829-36.

[62] Grossman A, Johannsson G, Quinkler M, Zelissen P. Therapy of endocrine disease: perspectives on the management of adrenal insufficiency: clinical insights from across Europe. Eur J Endocrinol 2013;169: R165-75.

[63] Williams GH, Braley LM, Underwood RH. The regulation of plasma 18-hydroxy 11-deoxycorticosterone in man. J Clin Invest 1976;58: 221-9.

[64] Flad TM, Conway JD, Cunningham SK, McKenna TJ. The role of plasma renin activity in evaluating the adequacy of mineralocorticoid replacement in primary adrenal insufficiency. Clin Endocrinol 1996;45:529-34.

[65] Ehrlich EN, Lindheimer MD. Effect of administered mineralocorticoids or $\mathrm{ACTH}$ in pregnant women. Attenuation of kaliuretic influence of mineralocorticoids during pregnancy. J Clin Invest 1972;51:1301-9.

[66] Lebbe M, Arlt W. What is the best diagnostic and therapeutic management strategy for an Addison patient during pregnancy? Clin Endocrinol 2013;78:497-502. 
[67] Methlie P, Husebye EE, Hustad S, Lien EA, Lovas K. Grapefruit juice and licorice increase cortisol availability in patients with Addison's disease. Eur J Endocrinol 2011;165:761-9.

[68] Bonfig W, Roehl FW, Riedl S, Dorr HG, Bettendorf M, Bramswig J, et al. Blood pressure in a large cohort of children and adolescents with classic adrenal hyperplasia $(\mathrm{CAH})$ due to 21-hydroxylase deficiency. Am J Hypertens 2016;29:266-72.

[69] Lovas K, Loge JH, Husebye ES. Subjective health status in Norwegian patients with Addison's disease. Clin Endocrinol 2002;56: 581-8.

[70] Arlt W, Callies F, van Vlijmen JC, Koehler I, Reincke M, Bidlingmaier $\mathrm{M}$, et al. Dehydroepiandrosterone replacement in women with adrenal insufficiency. N Engl J Med 1999;341:1013-20.

[71] Gurnell EM, Hunt PJ, Curran SE, Conway CL, Pullenayegum EM, Huppert FA, et al. Long-term DHEA replacement in primary adrenal insufficiency: a randomized, controlled trial. J Clin Endocrinol Metab 2008;93: 400-9.
[72] Srinivasan M, Irving BA, Dhatariya K, Klaus KA, Hartman SJ, McConnell JP, et al. Effect of dehydroepiandrosterone replacement on lipoprotein profile in hypoadrenal women. J Clin Endocrinol Metab 2009;94:761-4.

[73] Johannsson G, Burman P, Wiren L, Engstrom BE, Nilsson AG, Ottosson M, et al. Low-dose dehydroepiandrosterone affects behavior in hypopituitary androgen-deficient women: a placebo-controlled trial. J Clin Endocrinol Metab 2002;87:2046-52.

[74] Alkatib AA, Cosma M, Elamin MB, Erickson D, Swiglo BA, Erwin PJ, et al. A systematic review and meta-analysis of randomized placebocontrolled trials of DHEA treatment effects on quality of life in women with adrenal insufficiency. J Clin Endocrinol Metab 2009;94: 3676-81.

[75] Brooke AM, Kalingag LA, Miraki-Moud F, Camacho-Hubner C, Maher KT, Walker DM, et al. Dehydroepiandrosterone improves psychological well-being in male and female hypopituitary patients on maintenance growth hormone replacement. J Clin Endocrinol Metab 2006;91: 3773-9. 